\title{
Protocolos de atención en covid-19 asociado a pacientes pediátricos
}

\section{Care protocols in covid-19 associated with pediatric patients}

\author{
Protocolos de atención en covid-19
}

\author{
Dra. Johanna Sánchez Rodríguez ${ }^{1}$ \\ Lic. Margoth Elizabeth Villegas Chiriboga² \\ ${ }^{1}$ Universidad Estatal del Sur de Manabí /Universidad Laica Eloy Alfaro de Manabí, \\ johanna.sanchez@unesum.edu.ec/Johanna.sanchez@uleam.edu.ec, ORCID 0000-0002-7799-1151 \\ ${ }^{2}$ Universidad Estatal del Sur de Manabí/, margoth.villegas@unesum.edu.ec, ORCID 0000-0003-4637-5396
}

Recibido: 25-02-2020

Aprobado: 23-06-2020

Contacto: johanna.sanchez@unesum.edu.ec

\section{Resumen}

La enfermedad por el nuevo coronavirus ha generado una pandemia global, cuyos principales síntomas son respiratorios, varían desde un resfriado común hasta una enfermedad más grave como, neumonía, síndrome de dificultad respiratoria aguda grave, e incluso la muerte, también existe el grupo de pacientes asintomáticos portadores de la enfermedad. .

Los niños pueden enfermarse de COVID-19, aunque las probabilidades son menores. Dentro del cuadro clínico pueden presentar síntomas como cansancio, congestión nasal, diarrea o vómitos, aunque los síntomas se pueden confundir con otras enfermedades. El presente trabajo mediante una exhaustiva revisión bibliográfica ha elaborado un protocolo consensuado de atención de COVID 19 en pacientes pediátricos, Identificando los factores de riesgo que inciden en el contagio de covid19 en pacientes pediátricos, determinando las complicaciones y además ha diseñado diseñar un plan cuidados según las normas del cuerpo colegiado de enfermeras.

Palabras clave: Pandemia. Pacientes pediátricos, plan de cuidados.

\section{Summary}

The disease caused by the new coronavirus has generated a global pandemic, whose main symptoms are respiratory, ranging from a common cold to a more serious illness such as pneumonia, severe acute respiratory distress syndrome, and even death, there is also the group of patients asymptomatic carriers of the disease. .

Children can get sick from COVID-19, although the chances are lower. Within the clinical picture they may present symptoms such as fatigue, nasal congestion, diarrhea or vomiting, although the symptoms can be confused with other diseases. The present work, through an exhaustive bibliographic review, has developed a consensual protocol for the care of COVID 19 in pediatric patients, identifying the risk factors that affect the contagion of COVID19 in pediatric patients, determining the complications and also has designed to design a care plan according to the norms of the collegiate body of nurses.

Keywords: Pandemic. Pediatric patients, care plan.

\section{Introducción}

El 11 de marzo de 2020, la Organización Mundial de la Salud (OMS) consideró pandemia la infección por SARS-CoV-2. La enfermedad por coronavirus 2019 (covid-19, por sus siglas en inglés) fue descrita por primera vez en diciembre de 2019, en la ciudad de Wuhan, provincia de Hubei (China) (1).

Desde el inicio de la pandemia, la mayoría de reportes de vigilancia epidemiológica y publicaciones médicas han documentado que, a nivel mundial, aproximadamente $97-98 \%$ de todos los casos de COVID registrados ocurren en adultos. Del restante porcentaje que ocurre en niños, la mayoría de ellos cursa con infección leve o asintomática. De aquellos que requieren hospitalización en salas de emergencia, salas de pediatría o unidades de cuidados intensivos pediátricos (UCIP), la mayoría se debe a dificultad respiratoria y neumonía (2).

Los niños de todas las edades pueden contagiarse con la enfermedad del covid-19. Al igual que los adultos; los niños que tengan una enfermedad cardíaca congénita, afecciones genéticas, o enfermedades que afectan el sistema nervioso o el metabolismo, están propensos a un alto riesgo de enfermarse gravemente con el covid-19. Pero la mayoría de los niños afectados generalmente no se enferman con tanta gravedad como los adultos, y 


\section{HIGÍA DE LA SALUD}

algunos quizás no presenten ningún síntoma. A pesar de los grandes brotes epidémicos en todo el mundo, muy pocos niños han muerto (3).

Existen tres hipótesis sobre las causas por las que la covid-19 afecta menos a los niños. La primera sería la menor presencia de ECA2 en los pulmones de los niños, los ECA2 son unos receptores que están en las células que regulan la presión arterial, principalmente en los riñones y pulmones. $\mathrm{Al}$ entrar, el virus se adhiere a esos receptores y una vez dentro, el virus produce más copias suyas. Los niños tienen menos de estos receptores ACE2, entonces tienen menos posibilidad de tener menos infecciones por este virus. La segunda es la teoría del daño endotelial: el daño endotelial previo puede facilitar e incrementar la respuesta inflamatoria al SARS-CoV-2, sin embargo, en niños sanos el daño endotelial previo está prácticamente ausente. La tercera propone que la inmunidad innata — primera línea de defensa contra el SARS-CoV-2- está estimulada en niños por la adquisición de infecciones virales comunitarias y por el esquema de vacunación. Hasta la fecha, no hay vacunas o medicamentos específicos contra la covid-19, sin embargo, el tratamiento es sintomático. (1)

El virus covid-19 continúa extendiéndose por el planeta y ya ha infectado a más de 16,5 millones de personas, mientras que la cifra global de decesos rebasa los 600.000 y la de la recuperada roza los 9,5 millones de personas. El país más afectado es Estados Unidos, con más 4,3 millones de contagios y más de 148.000 fallecimientos, seguido de Brasil, que supera los 2,4 millones de casos y acumula más de 87.000 muertos. (4)

En Ecuador según el último reporte del MSP del 3 de agosto de 2020, existen 87.041 casos confirmados, de los cuales el $2,5 \%$ son en niños de 0 a 14 años de edad, es decir, 1.675 casos, ésta cifra ha ido aumentando según los últimos días. En Manabí, provincia del Ecuador, hasta la actualidad se han reportado más de 6000 casos confirmados, mientras que en la ciudad de Jipijapa, existen más de 300 casos. (5)

\section{Objetivos}

\section{Objetivo general}

Elaborar protocolos consensuados de atención de COVID 19 en pacientes pediátricos, por parte de los estudiantes de Séptimo semestre paralelo "A".

\section{Objetivos específicos}

- Identificar los factores de riesgo que inciden en el contagio de covid19 en pacientes pediátricos.

- Determinar las complicaciones por Covid19 en pacientes pediátricos.
Periodo. Enero - Junio 2020

Vol. 2, Nro. 1, Publicado 2020-06-30

- Diseñar un plan de cuidado para pacientes pediátricos con covid19.

Metodología

La metodología se basa en un estudio transversal, descriptivo prospectivo, se realizó la revisión de varias fuentes bibliográficas para obtener información y poder realizar el protocolo de atención en covid- 19 asociados a pacientes pediátricos. Se utilizaron métodos que permitieron profundizar el conocimiento, seleccionando para la investigación los siguientes:

- Método explicativo: Se basa en buscar porque se presentó este brote causado por coronavirus, la fuente primaria más probable de la enfermedad producida por el SARS-CoV-2, produciendo cuadros respiratorios, estableciendo las relaciones causa y efecto.

- Método de campo: Sirve para verificar y describir de qué manera afecta esta enfermedad a pacientes pediátricos y las posibles complicaciones de la misma.

\subsection{Diseño de estudio}

Es un estudio de tipo descriptivo realizado a Pacientes pediátricos, los niños son la población más susceptible de infectarse por lo tanto los niños deben participar en las acciones preventivas habituales para la contención y expansión de la infección, y la protección de los profesionales sanitarios es crucial en la valoración y exploración de los niños con infecciones respiratorias.

\section{Resultados}

\section{Medidas de prevención para los niños}

$\mathrm{Si}$ bien los niños no se encuentran en el grupo altamente vulnerable que desarrolla el COVID-19 a un nivel grave, no sabemos cómo va a responder su cuerpo ante la infección, cada persona es diferente. Ya se han reportado casos de personas jóvenes y sanas que desarrollan la enfermedad a un nivel grave e incluso han muerto. Esto nos hace reflexionar y priorizar los cuidados necesarios para evitar contraer el virus. (11)

Hay muchas medidas que se pueden tomar para prevenir que tu hijo se enferme con la COVID-19 y, si se enferma, para evitar contagiar a otros. La OMS recomienda medidas de prevención en los niños, dependiendo de la edad, explicarles y enseñarles cómo protegerse:

- $\quad$ Mantener las manos limpias. Hacer que se laven las manos con frecuencia con agua y jabón por lo menos durante 20 segundos. Si no dispones de agua ni jabón, usa un desinfectante de manos que contenga por lo menos un $60 \%$ de alcohol. Se cubran la boca y la nariz con el codo o un pañuelo descartable al toser o estornudar. Desechen el pañuelo descartable usado 


\section{HIGÍA DE LA SALUD}

y se laven las manos. Eviten tocarse los ojos, la nariz, y la boca.

Hagan que sus hijos se laven las manos inmediatamente después de volver a casa, así como después de usar el baño y antes de comer o preparar comida. Les muestren a sus hijos pequeños cómo crear pequeñas pompas de jabón al frotarse las manos, y cómo hacer entrar el jabón entre los dedos y hasta las puntas de los dedos, incluyendo los pulgares y el dorso de las manos. Los animen a que canten dos veces la canción entera de "Feliz cumpleaños" (aproximadamente 20 segundos) así pasan el tiempo que necesitan para limpiarse bien las manos.

\section{- Practicar el distanciamiento físico. Eviten} contacto cercano (menos de 6 pies o 2 metros) con cualquier persona que esté enferma o que presente síntomas. Reduzcan al mínimo las salidas de la casa. Si es posible, dejen a los niños en casa cuando salgan. Como las personas sin síntomas pueden contagiar el virus, no permitan que sus hijos se encuentren en persona para jugar con niños de otras casas - aunque todos ellos se sientan bien. Si sus hijos juegan afuera de la casa, asegúrense de que se mantengan a 6 pies (2 metros) de las personas que no vivan

En su casa. Pueden describir esta distancia a su hijo como el largo de una puerta, o una bicicleta para adultos.

No permitan que sus hijos jueguen a juegos o practiquen deportes en que compartan su equipo, como una pelota de básquetbol, o en los cuales no puedan mantener distancia física. Pospongan las visitas de su hijo en persona a adultos mayores. Animen a sus hijos a seguir en contacto con sus amigos y seres queridos a través de llamadas telefónicas o en conversaciones por video. Para mantener a sus hijos ocupados, consideren organizar comidas familiares virtuales, y noches de juegos, o encuentros virtuales para jugar con otros niños.

- Limpiar y desinfectar su casa. Concéntrense en limpiar todos los días las superficies que se tocan con frecuencia en las áreas compartidas de la casa, como mesas, perillas de puertas, sillas con respaldo duro, interruptores de luz, controles remotos, dispositivos electrónicos, manijas, escritorios, inodoros, y lavabos. También limpien las áreas que se ensucian con facilidad, como la mesa para cambiar al bebé, y las superficies que sus hijos tocan con frecuencia, como las superficies de su cama, la mesa de manualidades, la caja de los juguetes, y los juguetes. Usen agua y jabón para lavar los juguetes que sus hijos se pongan en la boca.

Asegúrense de enjuagar bien y de secar estos juguetes. Laven la ropa de cama de los niños y sus juguetes de peluche lavables, cuando sea necesario, y a la temperatura más alta posible. Sequen por completo estos artículos. Lávense las manos después de tocar las pertenencias de sus hijos. Si cuidan a un bebé con la COVID-19, lávense las manos después de
Periodo. Enero - Junio 2020

Vol. 2, Nro. 1, Publicado 2020-06-30

cambiar los pañales o de tocar la ropa de cama, los juguetes, o los biberones del bebé.

- Usar mascarillas de tela. se recomienda ponerse mascarillas de tela en lugares públicos, como el supermercado, donde es difícil evitar el contacto cercano con otros. Esto se recomienda especialmente en las áreas donde se ha propagado el virus en la comunidad. Este consejo está basado en datos que muestran que las personas con la COVID-19 pueden trasmitir el virus antes de darse cuenta de que lo tienen.

Si tu hijo tiene 2 años o más, haz que se ponga una mascarilla de tela cuando ustedes salgan de casa y a la comunidad, para prevenir la trasmisión de la COVID19 a otros. No les pongas una mascarilla a los niños menores de 2 años, a los niños que tengan cualquier problema para respirar, o a un niño que tenga una afección que le impida sacarse la mascarilla sin ayuda.

Además, continúa con las visitas de bienestar del niño, y actualiza sus vacunas. Esto es especialmente importante para los bebés y los niños menores de 2 años. Muchos proveedores de atención médica en comunidades afectadas por la COVID-19 están usando estrategias para separar las visitas para bienestar de las visitas para niños enfermos al atender a los niños enfermos en áreas separadas de sus consultorios o en ubicaciones diferentes. Si tu hijo debe ir a una visita de bienestar, habla con su médico sobre las medidas de seguridad que están tomando. No dejes que el miedo de contagiarse con el virus que causa la COVID-19 sea un obstáculo para que tu hijo se dé las vacunas que necesite. (12)

\section{Fármacos}

Los medicamentos descritos a continuación fueron mencionados en la investigación desarrollada y no están establecidos por la OMS como tratamiento definitivo para combatir la infección por covid-19, pero si para algunas de las complicaciones que son producidas a causa del virus. 


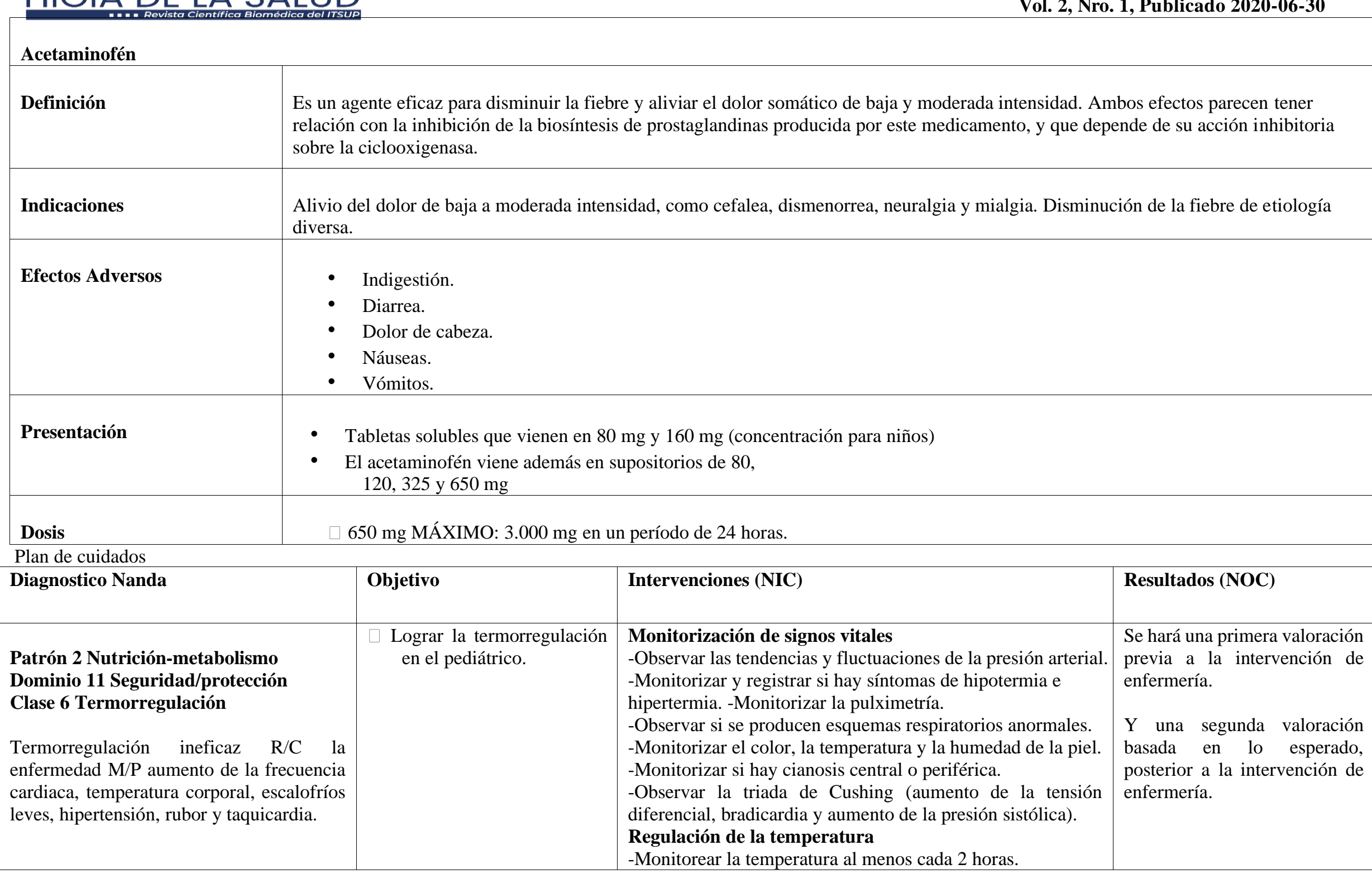




\begin{tabular}{|l|l|}
\hline & - Observar el color y la temperatura de la piel. -Observar y \\
& registrar si hay signos y síntomas de hipotermia e hipertermia. \\
-Favorecer una ingesta nutricional y de líquidos adecuada. & -Administrar la medicación antipirética. \\
& $\begin{array}{l}\text { Administración de la medicación } \\
\text {-Seguir los 10 principios para la administración de } \\
\text { medicamentos. }\end{array}$ \\
\hline
\end{tabular}

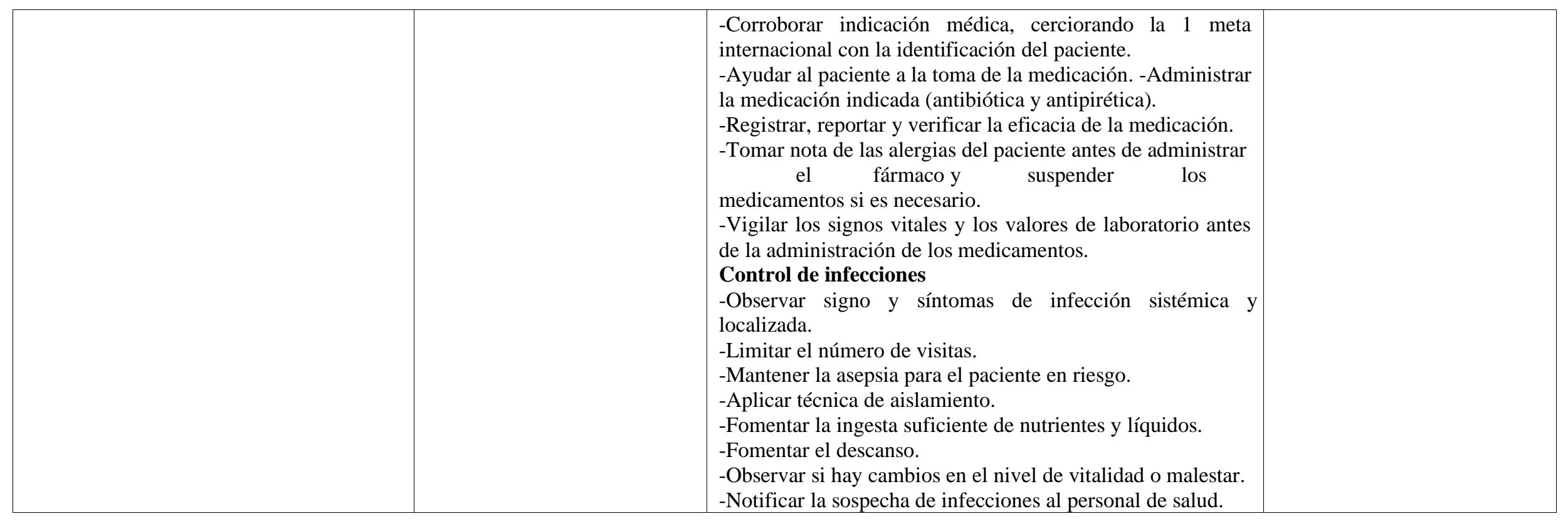

\begin{tabular}{|c|c|c|c|}
\hline DIAGNOSTICO NANDA & OBJETIVO & INTERVENCIONES (NIC) & RESULTADOS (NOC) \\
\hline
\end{tabular}


ISSN 2773-7705

HIGÍA DE LA SALUD

disminución de la presión inspiratoria,

disnea, taquipnea.
Periodo. Enero - Junio 2020

Vol. 2, Nro. 1, Publicado 2020-06-30

anotando los aumentos y

disminuciones de presiones

inspiratorias en volumen corriente. -

Valorar, registrar y referir el aumento

de la intranquilidad, ansiedad o

hiperventilaciones.

-Verificar y registrar saturación de

oxígeno.

Manejo del Equilibrio acido básico:

Acidosis

Respiratoria

-Mantener vía aérea limpia y

permeable.

-Monitorizar el patrón respiratorio.

-Obtener muestras de sangre para

determinar el equilibrio ácido base.

Manejo de Líquidos y Electrolitos

-Obtener muestras de sangre para

análisis de laboratorio (niveles de sodio

y potasio).

-Administrar diuréticos prescritos.

\begin{tabular}{|c|c|c|}
\hline 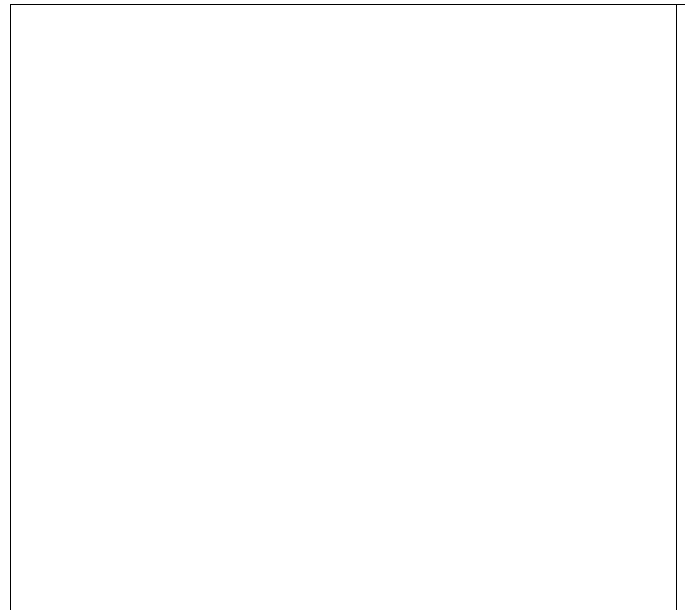 & . & $\begin{array}{l}\text {-Administrar suplemento de electrolitos } \\
\text { alterados -Verificar eficacia de la } \\
\text { medicación. } \\
\text { Intubación y Estabilización de Vías } \\
\text { Aéreas -Seleccionar el tipo y calibre de } \\
\text { la vía aérea: orofaríngea o nasofaríngea. } \\
\text {-Abordad la vía y asegurarse que el } \\
\text { dispositivo se encuentre en vía aérea y } \\
\text { fijar adecuadamente la cánula. } \\
\text {-Auscultar campos pulmonares, para } \\
\text { verificar la expansión bilateral de los } \\
\text { pulmones e inflar el balón endotraqueal. } \\
\text {-Verificar el tubo endotraqueal con } \\
\text { radiografía de tórax. } \\
\text {-Control de infecciones }\end{array}$ \\
\hline
\end{tabular}


HIGÍA DE LA SALUD DIAGNOSTICO NANDA

Dominio 11 Seguridad/protección

Clase 2 Lesión Física

Riesgo de shock R/C síndrome de respuesta inflamatoria sistémica

OBJETIVO

Evitar complicaciones en el paciente pediátrico con covid19.

INTERVENCIONES (NIC)

Manejo del equilibrio ácido-

base -Mantener la vía aérea

permeable.

-Colocar al paciente para facilitar una ventilación adecuada.

-Monitorizar las tendencias de $\mathrm{pH}$ arterial, $\mathrm{PaCo} 2$ y $\mathrm{HCO} 3$, para determinar tipo de desequilibrio y mecanismos fisiológicos

compensadores presentes. -Mantener la evaluación simultanea de $\mathrm{pH}$ arterial y de los electrolitos plasmáticos para una planificación terapéutica precisa.

-Monitorizar la gasometría arterial y los niveles de electrolitos séricos y urinarios. -Monitorizar el patrón respiratorio.

-Monitorizar los aportes tisulares de

oxígeno (hemoglobina, gasto cardiaco, $\mathrm{PaO} 2, \mathrm{SaO} 2$ ).

-Monitorizar los signos de insuficiencia respiratoria

-Monitorizar la determinación del consumo de oxígeno.

-Monitorizar el estado hemodinámico, incluidos los niveles de PVC, PAM, PAP, PECP.

-Monitorizar la perdida de bicarbonato

(drenaje de fístulas o diarrea).

-Monitorizar la pérdida de ácido

(vómito, aspiración, diarrea y uresis).

ISSN 2773-7705

Periodo. Enero - Junio 2020

Vol. 2, Nro. 1, Publicado 2020-06-30 RESULTADOS (NOC)

Se hará una primera valoración previa a la intervención de enfermería.

Y una segunda valoración basada en lo esperado, posterior a la intervención de enfermería. 
ISSN 2773-7705

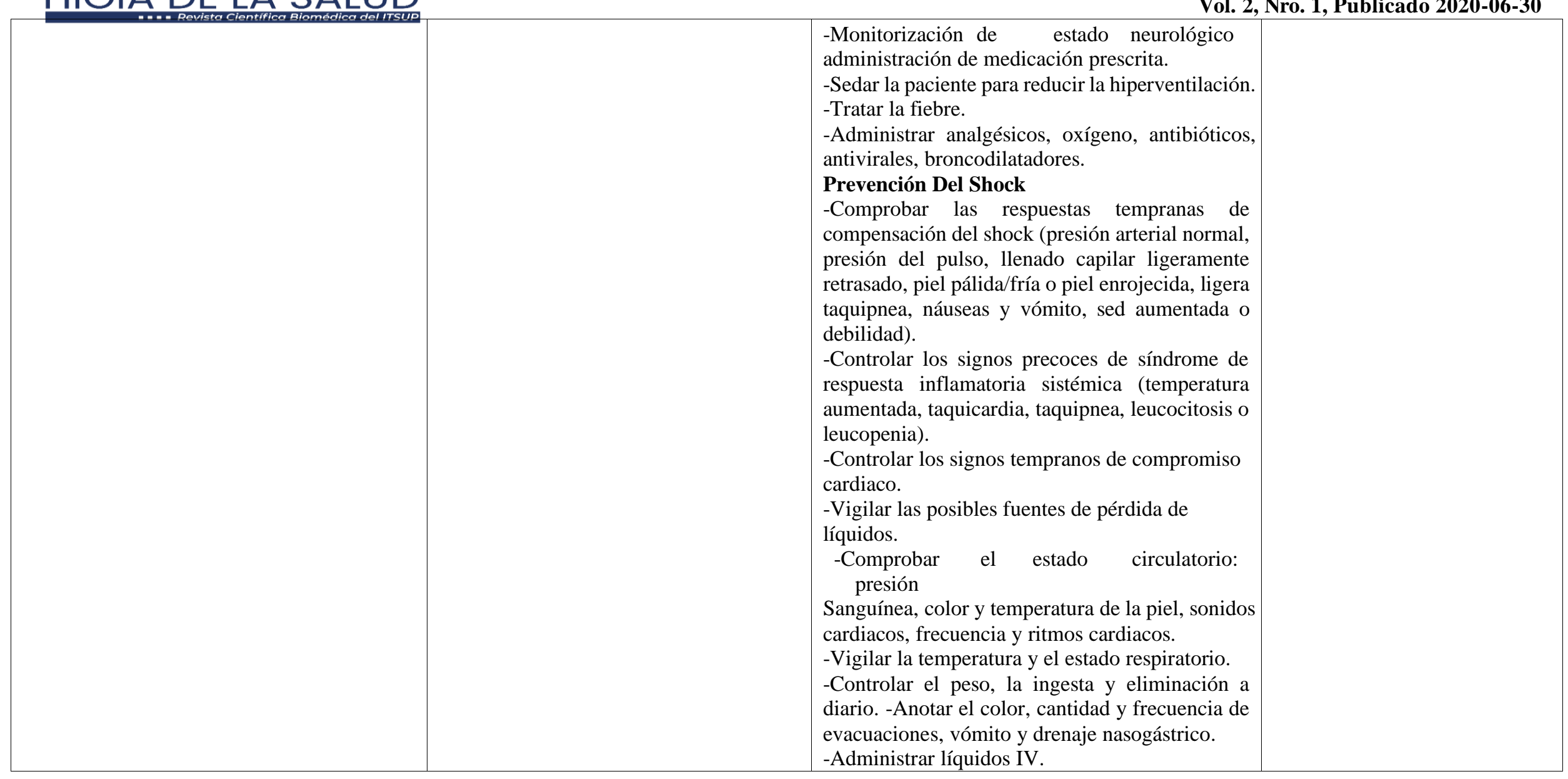


HIGÍA DE LA SALUD DIAGNOSTICO NANDA

Dominio 4 Actividad/reposo

Clase 4

cardiovasculares/pulmonares

Respuestas

Deterioro del intercambio de gases $\mathrm{R} / \mathrm{C}$ cambios de la membrana alveolo capilar M/P disnea, color anormal de la piel, confusión, diaforesis, disminución del nivel de dióxido de carbono, gasometría arterial anormal, hipoxemia, hipoxia, irritabilidad, $\mathrm{pH}$ arterial anormal, taquicardia.

\section{OBJETIVO}

Mejorar la capacidad del intercambio gaseoso y

lograr

una oxigenación

\section{INTERVENCIONES (NIC)}

Manejo De La Ventilación Mecánica Invasiva

Consultar con otros cuidados para la selección de

ventilación

-Asegurarse del buen funcionamiento y encendido de las alarmas del ventilador mecánico. -Administrar agentes paralizantes musculares, sedantes y analgésicos narcóticos prescritos.

-Controlar las actividades que aumenten el consumo de oxígeno (fiebre, escalofríos, convenciones, dolor actividades básicas de Enfermería que puedan sustituir los ajustes de soporte del ventilador y causar una de saturación de oxígeno.

-Vigilar la eficiencia de la ventilación mecánica sobre el estado fisiológico y psicológico del paciente.

-Realizar una técnica antiséptica en todos los procedimientos de sucesión.

Vol. 2, Nro. 1, Publicado 2020-06-30 RESULTADOS

(NOC)

Se hará una primera valoración previa a la intervención de enfermería.

Y una segunda valoración basada en lo esperado, posterior a la intervención de enfermería.

-Controlar la cantidad, color y consistencia de las secreciones pulmonares documentando los resultados. Aspiración de las vías aéreas

-Disponer precauciones universales: guantes, gafas protectoras y cubre bocas.

-Auscultar los sonidos respiratorios antes y después de la aspiración.

-En pacientes con COVID-19 no se recomienda híper oxigenar al paciente previo a la aspiración de secreciones.

-Dejar al paciente conectado al ventilador durante la aspiración, si se utiliza un sistema de aspiración traqueal cerrado.

- Observar el estado de oxígeno del paciente (niveles de $\mathrm{SaO} 2$ y SvO2) y estado hemodinámico (nivel de PAM y ritmo cardiaco) antes y después de la aspiración.

-Basar la duración de cada pase de aspiración traqueal en la necesidad de extraer secreciones y en la respuesta del paciente a la aspiración 


\begin{tabular}{|c|c|c|c|c|}
\hline & & \multicolumn{2}{|c|}{$\begin{array}{l}\text {-Aspirar la orofaringe después de terminar la aspiración } \\
\text { traqueal. } \\
\text {-Detener la aspiración traqueal y suministrar oxígeno } \\
\text { suplementario si el paciente experimenta bradicardia, un } \\
\text { aumento de ectopia ventricular y/o de saturación. } \\
\text {-Anotar el tipo y cantidad de secreciones obtenidas. } \\
\text { Protección de riesgo ambientales } \\
\text {-Valorar los riesgos posibles y reales del medio ambiente. } \\
\text {-Analizar el nivel de riesgo asociado con el entorno. } \\
\text {-Avisar a las instituciones autorizadas para proteger el } \\
\text { ambiente de peligros conocidos. } \\
\text {-Recomendar los diseños ambientales más seguros, sistema } \\
\text { de protección y el uso de dispositivos protectores. } \\
\text {-Someter a las poblaciones de riesgo a un tamizaje en busca } \\
\text { de signos de exposición a peligros ambientales. }\end{array}$} & \\
\hline \multirow[b]{2}{*}{$\begin{array}{l}\text { Dominio: 0011 SEGURIDAD } \\
\text { / PROTECCIÓN } \\
\text { Clase: 0001 INFECCIÓN } \\
\text { Limpieza ineficaz de las vías aéreas R/P } \\
\text { infección M/P alteración en el patrón } \\
\text { respiratorio, alteración de la frecuencia } \\
\text { respiratoria, disnea, ortopnea, tos inefectiva. }\end{array}$} & OBJETIVO & INTERVENCIONES (NIC) & RES & ULTADOS (NOC) \\
\hline & $\begin{array}{l}\text { Mantener vigilado al } \\
\text { paciente pediátrico, para } \\
\text { evitar } \\
\text { complicaciones. }\end{array}$ & 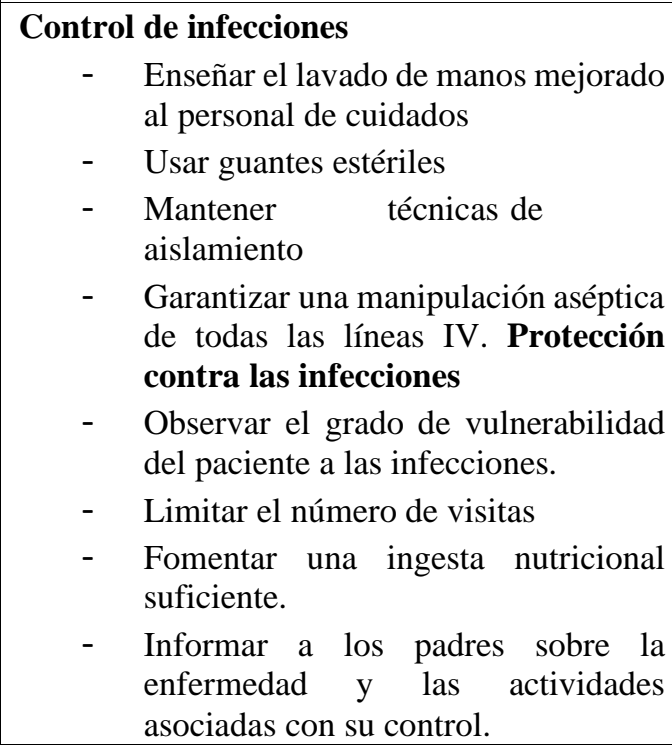 & \multicolumn{2}{|c|}{ 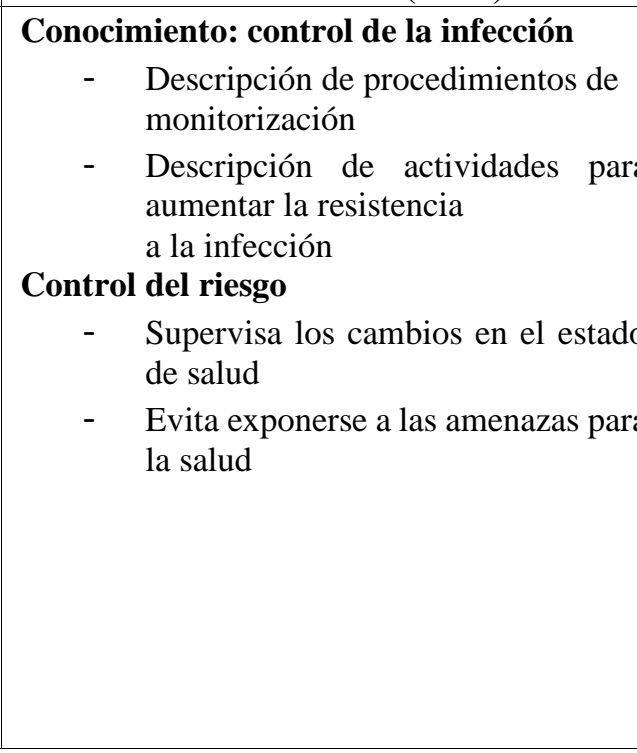 } \\
\hline
\end{tabular}


HIGÍA DE LA SALUD

DIAGNOSTICO NANDA

Dominio: 0009

Afrontamiento Y Tolerancia

Al Estrés

Clase: 0001 Respuesta

Postraumática

Afrontamiento infectivo R/P

sentimientos de los padres debido a

la exposición a epidemias $\mathbf{M} / \mathbf{P}$

preocupación, temor, llanto, fatiga.
OBJETIVO
Explicar a los padres todo lo relacionado del paciente pediátrico.

\section{Aumentar el afrontamiento}

- Disponer un ambiente de aceptación

- Alentar una actitud de esperanza realista como forma de manejar los sentimientos de impotencia

- Alentar el uso de fuentes espirituales

- Fomentar las actividades sociales y comunitarias

\section{Apoyo en la toma de decisiones}

- Facilitar la toma de decisiones en colaboración

- Proporcionar la información solicitada por los padres.

Vol. 2, Nro. 1, Publicado 2020-06-30 RESULTADOS (NOC)

Participación: decisiones sobre asistencia sanitaria

- Manifiesta autocontrol en la toma de decisiones

- Identifica apoyo disponible para conseguir los resultados deseados

Toma de decisiones

- Identifica las consecuencias posibles de

cada alternativa

\begin{tabular}{|c|c|c|c|}
\hline DIAGNOSTICO NANDA & OBJETIVOS & INTERVENCIONES DE ENFERMERÍA (NIC) & RESULTADOS (NOC) \\
\hline $\begin{array}{l}\text { DOMINIO: } 0004 \\
\text { ACTIVIDAD / REPOSO } \\
\text { CLASE: 0001 REPOSO / } \\
\text { SUEÑO } \\
\text { Fatiga r/p Estrés m/p Sentimientos de } \\
\text { culpa de los padres por no asumir la } \\
\text { enfermedad. }\end{array}$ & $\begin{array}{l}\text { Brindar apoyo emocional } \\
\text { a los padres del paciente } \\
\text { pediátrico con covid- } \\
19\end{array}$ & $\begin{array}{ll}\text { Ayuda al autocuidado } \\
\text { - } & \text { Establecer una rutina de actividades de } \\
& \text { autocuidados. Manejo ambiental } \\
\text { - } & \text { Fomentar crear un ambiente seguro. } \\
\text { - } & \text { Promover a eliminar los factores de peligro del } \\
& \text { ambiente. } \\
\text { - } & \text { Educar a los familiares cercanos acerca de los } \\
& \text { cambios y precauciones, de forma que no } \\
\text { interrumpan inadvertidamente el ambiente } \\
\text { Manejo de energía } \\
\text { - } \quad \text { Determinar la percepción de la causa de fatiga } \\
\text { por parte de los padres. } \\
\text { - } \quad \text { Facilitar actividades de recreo que induzcan } \\
\text { calma para favorecer la relajación }\end{array}$ & $\begin{array}{l}00003 \text { Descanso } \\
-\quad \text { Descansado mentalmente }\end{array}$ \\
\hline
\end{tabular}




\section{HIGÍA DE LA SALUD \\ Conclusiones}

- Para todas las personas, de cualquier edad, el principal factor de riesgo es estar en contacto con una persona portadora del virus, sin embargo los niños que poseen una enfermedad cardíaca congénita, afecciones genéticas y enfermedades que afectan el sistema nervioso o el metabolismo, están en un alto riesgo de enfermarse gravemente con COVID-19. Los recién nacidos pueden infectarse durante su nacimiento, en caso de que su madre sea portadora del virus, o por exposición a cuidadores enfermos después del parto.

- Según estudios realizados en la mayor parte del mundo, los niños tiene una baja incidencia de
Periodo. Enero - Junio 2020

Vol. 2, Nro. 1, Publicado 2020-06-30 contagios por covid-19, sin embargo, las principales complicaciones que se pueden presentar son, el síndrome de dificultad respiratoria, neumonía y bronquitis. Recientemente, se ha identificado una nueva enfermedad a causa del covid-19 en niños y adolescentes, como es el síndrome inflamatorio multisistémico llamado también enfermedad de Kawasaki, estas complicaciones, pueden llevar a los niños incluso a la muerte.

- Se realizó un plan de cuidados estandarizados, con el fin de identificar las necesidades reales y potenciales del paciente, para actuar o cubrir una necesidad, y así, ayudar en su recuperación.

\section{Colaboradores de la investigación:}

Alay García María José, Carrillo Santana Génesis Carolina, Cuenca Tóala Ángel Andrés, Chóez Suarez María Belén, Jaime Nieves Lady Joselyn, Manrique Catagua Tatiana Carolina, Rivadeneira Mera Helen Michelle, Ruiz De La Cruz Josselyn Stefania (estudiantes investigadores séptimo semestre carrera de enfermería)

\section{Referencias}

1. Llaque P. INFECCIÓN POR EL NUEVO CORONAVIRUS 2019. Rev Perú Med Exp Salud Pública. 2020.

2. Ulloa-Gutiérrez R. Síndrome inflamatorio multisistémico asociado a COVID-19. Rev Chilena Infecto. 2020; p.: 199.

3. clinica M. Mayo clinic. [Online]. 2020. Available from: https://www.mayoclinic.org/es-es/diseasesconditions/coronavirus/indepth/coronavirus-in-babies-and-children/art-20484405.

4. OMS JC. RTVE. [Online]. 2020. Available from: https://www.rtve.es/noticias/20200728/mapa-mundial-delcoronavirus/1998143.shtml.

5. PÚBLICA MDS. WWW.CORONAVIRUSECUADOR.COM. [Online]. 2020. Available from: https://www.salud.gob.ec/el-ministerio-de-salud-publica-delecuador-msp-informa-situacioncoronavirus/.

6. Organización Mundial de la Salud. Manejo clínico de la COVID-19. [Online]. 2020 [cited 202007 24. Available from: https://apps.who.int/iris/bitstream/handle/10665/332638/WHO-2019-nCoV-clinical2020.5spa.pdf? sequence $=1 \&$ isAllowed $=y$.

7. Instituto de Evaluación de Tecnologías en Salud e Investigación. EsSalud. [Online]. 2020 [cited 202007 24. Available from: http://www.essalud.gob.pe/ietsi/pdfs/guias/Recomendaciones_Pacientes_pediatricos_COVID.pdf.

8. Asociación Española de Pediatría (AEP). DOCUMENTO DE MANEJO CLINICO DEL PACIENTE PEDIÁTRICO CON INFECCION POR. [Online]. 2020 [cited 202007 24. Available from: https://www.seipweb.es/wpcontent/uploads/2020/03/29_3-AEP-SEIP-SECIP-SEUP.-DOCUMENTO-DEMANEJO-CLINICO-DELPACIENTE-PEDIAi\%CC\%80TRICO-Extracto-deldocumento-del-Ministerio.pdf.

9. Torres MTL. http://www.desastres.hn. [Online].; $2020 \quad$ [cited $2020 \quad 07 \quad 30 . \quad$ Available from: http://www.desastres.hn/COVID19/covid19guiasprovisionalesresumidasyextendidas/ProtocoloAtencionNino_COVI D19_Version2.0_28032020.pdf.

1 Elvia María Ardón. http://www.bvs.hn. [Online]. 2020 [cited 202007 30. Available

0. from: http://www.bvs.hn/COVID-19/Protocolo.COVID.pacientes.pediatricos.pdf.

1 Prisma. http://www.prisma.org.pe. [Online]. 2020 [cited 202008 03. Available

1. from: http://www.prisma.org.pe/blog-ninos/el-coronavirus-en-los-ninos-6-medidasde-prevencion/.

1 Mayo Foundation for Medical Education and Research.

2. https://www.mayoclinic.org. [Online]. 2020 [cited 202008 03. Available from: https://www.mayoclinic.org/es-es/diseases-conditions/coronavirus/indepth/coronavirus-in-babies-and-children/art20484405.

1 García Sánchez J, Rodríguez Arranz, García Vera C. https://www.aepap.org.

3. [Online]. 2020 [cited 202007 31. Available from: https://www.aepap.org/sites/default/files/noticia/archivosadjuntos/manejo_covid19_en_ap_pediatrica_gpi_aepap.pdf. 